\title{
Sander Govaerts
}

\section{Strijders voor natuur?}

\section{De complexe geschiedenis van legers en natuurbehoud.}

Vergeet Greenpeace, Natuurmonumenten en Ark. De Nederlandse natuur heeft een nieuwe engelbewaarder: Defensie. Militaire domeinen bieden vrijhavens voor allerlei zeldzame dieren en planten en hebben de terugkeer van de wolf in West-Europa mede mogelijk gemaakt. Deze bijdrage beargumenteert dat legers al eeuwenlang ecosystemen hebben beschermd en behouden, omdat dit militaire noden diende. De invloed van soldaten op natuur en milieu is zeer complex en omvat zowel destructie als natuurbehoud. Als de krijgsmacht wil bewijzen dat zij het beter doet dan middeleeuwse en vroegmoderne soldaten, dan heeft zij nog heel wat voor de boeg.

Defensie is niet bepaald een organisatie die men spontaan met natuurbescherming associeert. Toch spelen juist militaire organisaties, waaronder het Nederlandse leger, een belangrijke rol in milieubehoud anno 2019. Een belangrijk onderdeel van de zogenaamde Natura- 2000 gebieden, domeinen die van Europa speciale bescherming krijgen omwille van hun biodiversiteit, worden door de krijgsmacht beheerd. Dit geldt met name voor droge heide en zandduinen. Niels Gilissen, ecoloog bij Defensie en natuurfotograaf, publiceerde in 2013 zijn boek Missie Natuur, om deze kant van de krijgsmacht aan het grote publiek te tonen. ${ }^{1}$ In augustus 2018 mocht België zijn eerste wolvenpaar verwelkomen, op het militaire domein 'Kamp van Beverlo'. De kans is groot dat in mei-juli van dit jaar de eerste jongen geboren worden. ${ }^{2}$ Ook buiten Europa; in de Verenigde Staten, India en een aantal Afrikaanse landen, zoals Zuid-Afrika en Botswana, claimen militairen een belangrijke ecologische rol, hetzij door hun terreinbeheer, hetzij door de actieve bescherming van bedreigde diersoorten tegen stropers. ${ }^{3}$ 


\section{Govaerts}

\section{De Natuur onder vuur}

Betekent dit nu dat legers anno 2018 'groen' zijn geworden? Niet helemaal, zo blijkt. Defensie levert een wezenlijke bijdrage aan de Nederlandse biodiversiteit, omdat het landschappen in stand houdt die elders door industrialisatie en intensivering van de landbouw (met name vanaf 1850) zijn verdwenen. Dit is een onbedoeld effect van militaire trainingsactiviteiten, dat echter wel handig uitgebuit wordt om de publieke opinie te beïnvloeden. In de tweede helft van de twintigste eeuw kwamen militairen in heel West-Europa onder druk te staan omwille van de ecologische schade die zij veroorzaakten. In Nederland verscheen bijvoorbeeld het boekje Natuur onder vuur van de Werkgroep Ekologie in 1985. De schrijvers waren voornamelijk verontwaardigd over het gebruik van chemische- en atoomwapens, maar wezen ook op de gevaren van erosie, vervuiling en geluidsoverlast veroorzaakt door het leger. ${ }^{4}$ Deze kritiek is nooit helemaal verstomd. Het NAVO-vliegveld nabij Schinveld, bijvoorbeeld, kwam de laatste jaren onder vuur te liggen, nadat waardevol bosgebied gekapt moest worden, om de vliegtuigen niet te hinderen. ${ }^{5}$

Defensieorganisaties noemen zich 'milieubewust' en 'groen' om te rechtvaardigen dat zij enorme stukken land afsluiten van de buitenwereld of zelfs confisqueren. De Engelse geografe Rachel Woodward heeft een aantal pionier studies geschreven, waarin zij het discours van het Britse Ministerie van Defensie aanklaagt. De militaire terreinen op Salisbury Plain bijvoorbeeld zijn de grootste van Engeland en omvatten meer dan driehonderdnegentig vierkante kilometer. Een aantal dorpen zijn zelfs ontruimd om dit mogelijk te maken. ${ }^{6}$ In de laatste jaren worden beperkte vormen van recreatie, zoals wandelen en fietsen (maar ook jagen) steeds meer toegestaan, om een publiek draagvlak te creëren. Het gevaar bestaat echter dat een belangrijk positief aspect van militaire domeinen, het feit dat menselijke verstoring relatief beperkt blijft, hierdoor tenietgedaan wordt.

Steeds opnieuw blijkt immers dat militairen enkel 'groen' willen zijn zolang het geen beperkingen oplegt aan militaire noden. Dat betekent dus ook dat departementen van defensie zich in eigen land kunnen profileren als 'milieubewust', maar in buitenlandse missies zich daar weinig of helemaal niets meer van aantrekken. Met name het Amerikaanse leger heeft een twijfelachtige reputatie op dit vlak. Een recent rapport uit 2008 over het belang van milieuoverwegingen voor militaire operaties wees erop dat deze niet systematisch in planning worden betrokken. De onderzoekers 
benadrukten dat milieuvervuiling een negatief effect kan hebben op relaties tussen militairen en de plaatselijke bevolking en ook de gezondheid van de troepen zelf kan aantasten. We leven in een tijd waarin nieuwsberichten over klimaatopwarming en milieurampen nooit ver weg zijn, maar blijkbaar zijn dergelijke overwegingen niet vanzelfsprekend. ${ }^{7}$

$\mathrm{Nu}$ zou je natuurlijk kunnen stellen dat milieubewegingen een recent fenomeen zijn, (van na de Tweede Wereldoorlog) en dat de problemen die hier worden aangekaart slechts kinderziektes zijn. Dit is helaas niet zo. Militairen kunnen zich opwerpen als zijnde 'milieubewust' en zelfs 'progressief', omdat zowel zijzelf als hun critici een zeer vertekend beeld ophangen van de historische werkelijkheid. Duitse milieuactivisten vergeleken in 1988 het West-Duitse leger met 'roofridders' en 'middeleeuwse huurlingen' en de Franse journalist Nicolas Skrotzky haalde in 1991 er zelfs Dzjengis Khan en de Mongoolse invasies bij. Meer stereotiepe visies op middeleeuwse oorlogsvoering zijn niet zo snel te vinden. In de meeste gevallen worden historische voorbeelden van de ecologische impact van legers simpelweg niet vermeld, mogelijk omdat iedereen ervan uitgaat dat milieuproblemen (en bescherming) het alleenrecht zijn van de 'moderne mens'.

\section{Waterlinies en groene vestingwerken}

Als je de huidige problematiek even achterwege laat en met een open blik naar historische bronnen kijkt (kronieken, middeleeuwse rekeningen, militaire handboeken, correspondentie) dan valt onmiddellijk op dat legers al eeuwenlang voor de komst van moderne milieubewegingen ecosystemen hebben beschermd en biodiversiteit hebben bevorderd. Zij deden dat simpelweg omdat het militaire noden diende. Een zeer goed voorbeeld voor de Nederlandse context specifiek is de Hollandse Waterlinie, of beter gezegd: de Oude en Nieuwe Hollandse Waterlinie (van respectievelijk 16721795 en 1815-1956). Deze linies bestonden uit een aaneengesloten serie van inundaties, forten en artilleriestellingen die Holland, als zijnde het kerngewest van de Republiek en later het Koninkrijk Nederland, voor een invasie moesten behoeden. De toevoeging van forten en artilleriestellingen was noodzakelijk om de toegangen door de waterlinie (dijken) alsook de inundatiesluizen, te beveiligen. De gebieden die daadwerkelijk deel uitmaakten van de Hollandse Waterlinies waren niet permanent overstroomd, maar moesten daar wel op voorbereid zijn. De waarde van de Hollandse Waterlinies, zichtbaar tot op de dag van vandaag, ligt dus in het behoud van waardevol nat grasland 


\section{Govaerts}

en moerasgebied, dat anders ontwaterd zou zijn om plaats te maken voor landbouw. ${ }^{9}$

Ook de voormalige vestingwerken van garnizoenen zoals Maastricht en 's-Hertogenbosch worden door ecologen als zeer waardevol bestempeld omwille van de zeldzame muurplanten en korstmossen die hier voorkomen. ${ }^{10}$ Sommigen van de grootste vleermuiskolonies in West-Europa worden ook in verlaten bunkers of forten teruggevonden. Deze bieden constante temperaturen en een relatief hoge vochtigheidsgraad. Dit lijkt een mooi voorbeeld van de nauwe band tussen natuur en vrede (dieren en planten claimen hun rechtmatige plaats en oorlogsstructuren vervallen tot ruïnes), maar de realiteit is veel complexer. In praktijk is menselijk ingrijpen vaak vereist om ervoor te zorgen dat deze voormalige vestingwerken niet tot puinhopen vervallen. Dat zou immers ook betekenen dat deze unieke biotopen verdwijnen. ${ }^{11}$ (afb.1).

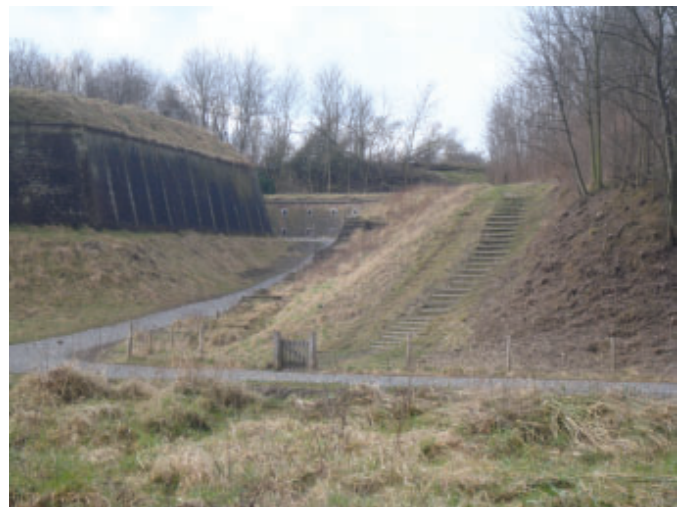

Afb. 1. De Hoge Fronten in Maastricht (foto door de auteur).

De Hoge Fronten in Maastricht, die een belangrijk deel van de achttiende-eeuwse fortificaties van de stad omvatten, zijn nu beschermd als natuurreservaat omwille van de zeldzame soorten die daar leven. Hier huist de meest noordelijke populatie van de muurhagedis in Europa. Deze vestingwerken worden beheerd op een manier die opvallend gelijkwaardig is aan onderhoudswerken van het voormalige garnizoen: de begrazing gebeurt door schapen en de meeste bomen en struiken zijn verwijderd. Vroegmoderne fortificaties in de Nederlanden waren immers zelden van steen, maar waren meestal gemaakt van aarde, blokken gras en takkenbossen. Dit was veel goedkoper dan natuur- of baksteen en minstens zo effectief tegen artillerievuur. Het enige nadeel was dat deze muren zeer kwetsbaar waren voor erosie. Begrazing door schapen of extensief maaibeheer (maximum twee keer per jaar) was dus een praktische manier om onderhoud te verzekeren. Het had ook het voordeel dat extra inkomsten werden gegenereerd: een schapenhandelaar betaalde de gouverneur voor het recht zijn schapen te 
weiden of het gemaaide gras werd verkocht als hooi. ${ }^{12}$

Voor een aantal Nederlandse versterkingen kunnen we zelfs vrij goed reconstrueren welke plantensoorten hier voorkwamen toen zij nog actief door militaire garnizoenen beheerd werden. Er zijn namelijk een aantal publicaties van negentiende-eeuwse naturalisten bewaard gebleven (o.a. voor Maastricht, 's-Hertogenbosch en Nijmegen). Deze onderzoekers, vooral botanici, konden de vestingwerken nog als unieke biotopen bestuderen voordat zij verlaten of afgebroken werden. Hun resultaten bevestigen dat de fortificaties een thuis boden aan een enorme variëteit aan planten: grassen, kruiden, waterplanten, mossen, een logisch gevolg van de diversiteit van de fortificaties zelf (muren, grasland, watergrachten) en het extensief beheer. Niet minder belangrijk is dat toegang tot deze gronden ook zeer beperkt was. Burgers mochten hier enkel met uitzonderlijke toestemming komen (enkel de oude stadsmuur stond open voor wandelaars). ${ }^{13}$

Deze opmerkelijke ecologische invloeden van vroegmoderne legers kunnen nog verder doorgetrokken worden naar de Middeleeuwen. Men moet er alleen rekening mee houden dat er toen nog geen strikt onderscheid werd gemaakt tussen strijders en niet-

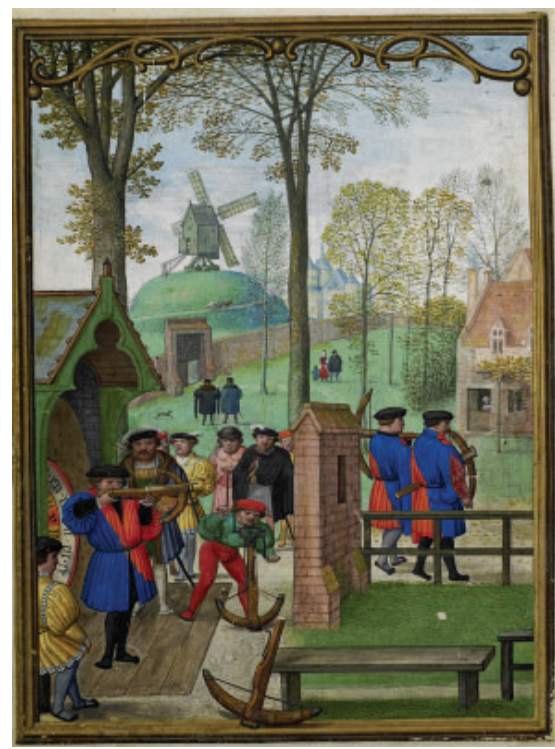

Afb. 2. Schutterstuin, vroege zestiende eeuw (Brussel, Koninklijke Bibliotheek, ms. II 158 Livre d'Heures, November, f. 11 v.). strijders. Er waren zeker mensen die van oorlog voeren min of meer hun beroep maakten (soldaten), maar een strikt onderscheid tussen burgers en militairen kwam pas op het einde van de achttiende en het begin van de negentiende eeuw tot stand. ${ }^{14}$ Middeleeuwse stadsmuren en kastelen wemelden al van het leven: karpers leefden in watergrachten of vijvers, doornstruiken vervulden een gelijkaardige functie als prikkeldraad en de aanleg van tuinen nabij vestingmuren was zeer gebruikelijk. De Universiteit van Amsterdam en de Universiteit Leiden zijn zelfs deels gelegen in vroegere schutterstuinen, waar deze gilden hun schietoefeningen hielden. ${ }^{15}$ (Afb. 2). 


\section{Govaerts}

Bosgebieden vervulden eveneens een zeer belangrijke rol in grensgebieden, als barrière tegen vijandelijke aanvallen. Een van de meest gebruikelijke acties in oorlogstijd was het afsluiten van mogelijke invasieroutes, door bruggen af te breken en wegen met omgehakte bomen te versperren. Dergelijke tactieken zijn vooral effectief in landschappen die op zich al vrij ontoegankelijk zijn, zoals moerassen en bossen. De noodzaak zich voor te bereiden op oorlog zorgde ervoor dat dergelijke stukken 'wildernis' in grensgebieden werden behouden. Het idee van de Hollandse Waterlinie heeft dus middeleeuwse voorlopers. In uitzonderlijke gevallen konden houtvesters zelfs soldaten aannemen om stroperij en illegale houtkap in te dammen. ${ }^{16}$

\section{Oorlog en wildernis}

Zelfs oorlog betekende niet noodzakelijk een ecologische ramp. Al in de vroege dertiende eeuw legt de cisterciënzer Caesarius van Heisterbach (ca. 1180- ca. 1240) een verband tussen oorlog en de toegenomen aanwezigheid van wolven. ${ }^{17}$ Het interessante aan de wolf is dat het één van de weinige dieren is waarvan we het historisch verspreidingsgebied min of meer kunnen reconstrueren aan de hand van historische bronnen. Wolven werden immers als 'ongedierte' bestempeld, dat betekende dat er premies voor dode exemplaren werden uitgekeerd. Deze lijsten van uitgekeerde beloningen wijzen erop dat de wolvenpopulatie in de Nederlanden gedurende de Tachtigjarige Oorlog inderdaad toenam. Rond 1600 doken er zelfs wolven aan de Nederlandse kust op, in de Langstraat (het gebied tussen Geertruidenberg en 's Hertogenbosch). ${ }^{18}$

De reactie van tijdgenoten is ook zeer verhelderend: volgens hen kon oorlog niet alleen tot ecologische schade leidden, maar zorgde het ook voor een toename van 'wildernis' of ongecontroleerde natuur. Doornstruiken palmden verlaten velden in en hagen groeiden uit tot kleine bossen. De menselijke invloed op het landschap was al rond het jaar duizend al zo verregaand dat de meeste grote zoogdieren, symbolen van 'Europese wildernis', zoals de beer, de oeros, de eland, de lynx en de wisent, uit Nederland verdwenen waren of op de rand van uitsterven stonden. Oorlog verminderde de menselijke invloed op ecosystemen en gaf 'ongewenste' soorten de kans zich weer te verspreiden. Tijdens periodes van conflict werd de jacht immers stilgelegd en bleven velden braak liggen doordat dorpelingen zich in hun kerk verschansten of naar nabijgelegen steden en kastelen moesten vluchten. Met name wolven werden in vredestijd meedogenloos vervolgd 
(Afb. 3). In zekere zin had oorlog dus een gelijkaardig effect als Europese beschermingsmaatregelen voor wolven in de laatste decennia. ${ }^{19}$

Menselijke invloed was zeker niet altijd negatief voor de biodiversiteit,

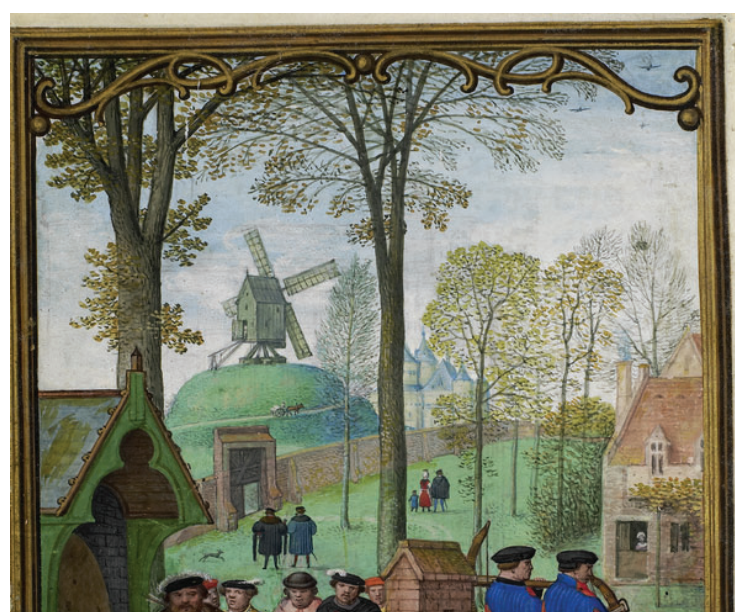

Afb. 3. Wolvenjacht, late zestiende eeuw, gravure door Joannes Stradanus (1523-1605) (Amsterdam, Rijksmuseum, Objectnummer RP-P-1982-173). dieren zoals het konijn, de karper, het damhert, de fazant en de knobbelzwaan zijn ook in de Middeleeuwen uit andere streken ingevoerd, of hun verspreiding werd sterk gestimuleerd. Het aantal planten dat toen in Nederland werd geïntroduceerd (met name kruiden uit Mediterrane regio's) is nog veel groter. Andere dieren, zoals het everzwijn en edelhert, konden enkel overleven omdat zij in speciale parken werden gehouden, als adellijk jachtwild. Tegenwoordig wordt de introductie van nieuwe soorten vaak als problematisch aanzien omdat deze invasief kunnen worden. De meeste dieren en planten die voor 1800/1850 (voor de uitvinding van stoomschepen en spoorwegen) naar West-Europa migreerden kwamen uit relatief nabije regio's en zorgden dus niet voor al te grote moeilijkheden. ${ }^{20}$

Legers hadden een belangrijke, vaak positieve impact, op biodiversiteit, omdat hun belangen meestal haaks staan op die van andere sociale groepen, met name landbouwers. Zij droegen bij tot een verscheidenheid aan menselijke invloeden die op hun beurt de biodiversiteit bevorderen. Het is zeer simplistisch te denken dat echte 'natuur' enkel kan bestaan als het met een groot hek afgesloten wordt van menselijke invloed (zoals in de Oostvaardersplassen). Het concept 'ecosysteem' impliceert juist dat levende en niet-levende wezen; mensen, dieren, planten, water, bodem, weer en klimaat, onlosmakelijk met elkaar verbonden zijn. ${ }^{21}$

De ecologische invloed van legers in het verleden kon echter wel degelijk problematisch zijn. Zij hebben immers ook een wezenlijke bijdrage 


\section{Govaerts}

geleverd aan industrialisatie (vooral de ijzerindustrie). Zo kapten ze massale hoeveelheden hout, stroopten ze en verspreidden ze ziektes. Het doel van deze bijdrage is zeker niet te ontkennen dat militaire organisaties enorme ecologische schade kunnen veroorzaken, maar wel erop te wijzen dat legers al een wezenlijke bijdrage leverden aan de bescherming en het behoud van ecosystemen voordat moderne milieubewegingen werden opgericht. Militairen vandaag de dag doen in wezen simpelweg wat hun voorgangers al eeuwenlang deden: zij dragen bij tot milieubescherming omdat militaire noden biodiversiteit kunnen bevorderen.

\section{Naar een groene Defensie}

Wat betekent deze uiteenzetting nu voor de claim dat Defensie 'groen' is geworden? De 'positieve' bijdragen van legers zijn min of meer hetzelfde gebleven of hebben slechts relatief aan belang gewonnen door veranderingen in de samenleving als geheel (intensivering van de landbouw, bevolkingstoename, etc.), terwijl hun destructieve en vervuilende acties exponentieel zijn toegenomen. Middeleeuwse en vroegmoderne soldaten kapten bomen om en stroopten dieren, maar die acties zijn uiteindelijk relatief beperkt in vergelijking met atoomwapens, biochemische oorlogsvoering en massaal verbruik van fossiele brandstoffen. Als militairen zich echt 'groen' willen noemen, zullen ze het woord 'defensie' veel ruimer moeten gaan opvatten dan dat ze nu doen. De krijgsmacht zal zich veel moeten inzetten om een ecologisch bewustzijn onder hun leden te creëren. Milieubehoud moet een integraal onderdeel van hun acties en beleid gaan uitmaken. Het wordt tijd dat het Ministerie van Defensie inziet dat het inperken van zijn ecologische voetafdruk essentieel is om hun eigen gezondheid en die van de samenleving als geheel te waarborgen.

\section{Noten}

1. Niels Gilissen, Missie Natuur: Natuur en landschap op defensieterreinen (Zeist: KNNV Uitgeverij, 2013).

2. Katrien Boon, "Wolf August liep 350 kilometer om Naya te ontmoeten en beet wel degelijk Limburgse schapen dood," 24 augustus 2018 https:/www.vrt.be/vrtnws/ nl/2018/08/24/wolf-august-liep-300-kilometer-om-naya-te-ontmoeten-en-beet-wel/. Geraadpleegd op 27 oktober 2018. 
3. Sarah Brunel, Les missions militaires au service de la biodiversité. (Les Ulis: EDP sciences, 2012); Dan Henk, "Biodiversity and the Military in Botswana," Armed Forces and Society 32:2 (2006): 273-291.

4. Freek van Mourik, Hans van Teijlingen, and Paul Vertegaal, De natuur onder vuur: Milieu-effekten van militaire aktiviteiten (Utrecht: Ekologie, 1985).

5. Persbureau ANP, "Geen dwangsom Rijk om bomenkap in Schinveld," 10 januari 2018 https://www.1limburg.nl/geen-dwangsom-rijk-om-bomenkap-schinveld. Geraadpleegd op 27 oktober 2018.

6. Rachel Woodward, "Khaki Conservation: An Examination of Military Environmentalist Discourses in the British Army," in Journal of Rural Studies 17:2 (2001): 201-217.

7. David E. Mosher David et al., Green Warriors. Army Environmental Considerations for Contingency Operations from Planning Through Post-Conflict (Santa Monica CA: RAND Corporation, 2008).

8. Jochen Lange, "Raus aus den Kartoffeln... Möglichkeiten der politischen Gegenwehr," in Natur ohne Frieden. Die Umweltsünden der Bundeswehr: Militär kontra Natur, ed. Olaf Achilles (München: Knaur, 1988), 207-234. Gerd Schuster,“Täuschen und Tarnen. Eine natur- artikel und die Folgen"' in Natur ohne Frieden, 13-28; Nicolas Skrotzky, Guerres crimes écologiques (Paris: Sang de la Terre, 1991).

9. Maarten Ridderbos, Kleine atlas van de Oude Hollandse Waterlinie (Amsterdam: Mijn Eigen Boek, 2010). Chris Will, Sterk water. De Hollandse Waterlinie (Utrecht: Matrijs, 2002).

10. Jan Maassen en Henk Vennix, De groene vestingmuren van 's Hertogenbosch. Korstmossen onder de loep ('s Hertogenbosch: Adr. Heinen Uitgevers, 2007). Eduard J. Weeda, "Maastricht," in Plants and Habitats of European Cities, ed. John G. Kelcey en Norbert Müller (Heidelberg: Springer, 2011), 237-274.

11. Martijn Boosten, Patrick Jansen en Ido Borkent, Beplantingen op verdedigingswerken: Geschiedenis Beheer Praktijkvoorbeelden (Utrecht: Uitgeverij Matrijs, 2012).

12. Sander Govaerts, "Mosasaurs: Interactions Between Armies and Ecosystems in the Meuse Region, 1250-1850" (PhD Thesis University of Amsterdam, 2019), 110-111.

13. Govaerts,"Mosasaurs," 120-126.

14. Gunner Lind, "Genesis of the Civilian in the Western World, 1500-2000," in Civilians at War: From the Fifteenth Century to the Present, ed. Gunner Lind (Copenhagen: Museum Tusculanum Press, 2014), 47-82.

15. Govaerts, "Mosasaurs," hoofdstukken 2 en 3.

16. Govaerts, "Mosasaurs," 50, 183.

17. Caesarius von Heisterbach, Dialogus Miraculorum, ed. Josephus Strange (Keulen; Bonn; Brussel, 1851), vol. 2, 260-261.

18. Han Verschure, Overleven buiten de Hollandse Tuin. Raamsdonk, Waspik, 's Gravenmoer, Capelle, Sprang en Besoijen tijdens de Tachtigjarige Oorlog (Tilburg, 2004), 262-268.

19. Govaerts, "Mosasaurs" hoofdstuk 4.

20. Richard C. Hoffmann, "Environmental Change and the Culture of Common Carp in Medieval Europe," in Guelph Ichthyology Reviews 3 (1995): 57-85; Roel C.G.M. 


\section{Govaerts}

Lauwerier en Jorn T. Zeiler, "Wishful Thinking and the Introduction of the Rabbit in the Low Countries," Environmental Archaeology 6 (2001): 87-90; A.C. Zeven et al., De introductie van onze cultuurplanten en hun begeleiders, van het Neolithicum tot $1500 A D$ (Wageningen: Vereniging voor Landbouwgeschiedenis, 1997).

21. Frank Benjamin Golley, A History of the Ecosystem Concept in Ecology: More than the Sum of the Parts (New Haven: Yale University Press, 1996). 